\title{
RACIONALIDADES E AMBIVALÊNCIAS DA GESTÃO CULTURAL
}

\section{RATIONALITIES AND AMBIVALENCES OF CULTURAL MANAGEMENT}

\author{
ADRIANA ALMEIDA DO CARMO \\ PPG em Administração da Pontifícia Universidade Católica de Minas Gerais (PUC MINAS) \\ Doutoranda do Programa de Pós-graduação em Administração - PUC Minas \\ Orcid: http://orcid.org/0000-0002-8398-2198 / E-mail: gestaodecultura@gmail.com \\ Rua Perdigão Malheiros, 686, apto 401 - Bairro Coração de Jesus - BH/MG - CEP: 30380-234.
}

\section{CLÁUDIA APARECIDA AVELAR FERREIRA}

PPG em Administração da Pontifícia Universidade Católica de Minas Gerais (PUC MINAS)

Doutoranda do Programa de Pós-graduação em Administração (PUC MINAS)

Orcid: http://orcid.org/0000-0002-8802-1716 / E-mail: claudiahgv@gmail.com

\section{ARMINDO DOS SANTOS DE SOUSA TEODÓSIO}

Professor do PPG em Administração da Pontifícia Universidade Católica de Minas Gerais (PUC MINAS) Doutor em Administração de Empresas - Escola de Administração de Empresas de São Paulo (EAESP) Orcid: http://orcid.org/0000-0002-7835-5851 / E-mail: armindo.teodosio@gmail.com

Submissão: 16/07/2019. Revisão: 24/04/2020. Aceite: 07/07/2020. Publicação: 03/08/2020. DOI: http://dx.doi.org/10.22277/rgo.v13i3.5245

\section{RESUMO}

O objetivo do estudo foi trazer apontamentos e reflexões acerca da gestão cultural a partir das racionalidades e seus paradoxos, vivenciados por um gestor cultural através da autoetnografia. Na gestão cultural há prevalência da racionalidade substantiva, entretanto, não se pode negar a importância das demais racionalidades: comunicativa e instrumental, para atingimento dos objetivos propostos. O estudo traz as ambivalências a que o gestor do campo da cultura está submetido e subordinado (ambiente externo) e demais complexidades da área, como a prestação de contas e enfatiza como a memória é substancial para a utilização dessa metodologia. O estudo aponta, também, a importância da cultura nos territórios periféricos.

Palavras-chave: Gestão Cultural. Racionalidades. Gestor Cultural. Autoetnografia. Território.

\section{ABSTRACT}

The aim of the study was to bring notes and reflections on cultural management from rationalities and their paradoxes, experienced by a cultural manager through selfethnography. In cultural management there is a prevalence of substantive rationality, however, one cannot deny the importance of other rationalities: communicative and instrumental, in order to achieve the proposed objectives. The study brings the ambivalences that the cultural field manager is subjected to and subordinate (external environment) and other complexities of the area, such as accountability and emphasizes how substantial memory is for the use of this methodology. The study also points out the importance of culture in the peripheral territories.

Keywords: Cultural Management. Rationalities. Cultural Manager. Auto Ethnography. Territory. 


\section{INTRODUÇÃO}

O campo da cultura, historicamente, amarga a baixa atenção pública representada por diversos fatores como: insignificante apoio de políticos, falta de qualidade de seus técnicos, escolha errônea de dirigentes de cúpula (DURANT, 1996; LIMA, 2004; DIAS; COSTA, 2018). Além disso, há também os questionamentos sobre a aplicação dos recursos destinados à Lei Rouanet. Nesse cenário há, por outro lado, pouca valorização de alguns tipos de manifestação da cultura, permanecendo, de forma majoritária, no gueto das classes média e alta as formas culturais mais valorizadas, o que se observa em sociedades desiguais, como a brasileira (ROCHA, 2004; MARINO, 2015). Além desses aspectos, esse campo demanda, cada vez mais, profissionais que suportem o gerenciamento de todas as atividades relacionadas à cultura e à sua promoção na administração pública e privada, bem como à utilização dos mecanismos de incentivos fiscais.

A cultura é interpretada por Clifford Geertz, em 1973, como "um universo de símbolos e significados que permite a um grupo interpretar suas experiências e guiar suas ações" (GEERTZ, 2008, p. 20). Geertz (1989, p. 15) apresenta a cultura sobre outro olhar, demonstrando a necessidade de uma explicação:

\footnotetext{
Acreditando, com o Max Weber, que o homem é um animal amarrado a teias de significados que ele mesmo teceu, assumo a cultura como sendo essas teias e a sua análise; portanto, não como uma ciência experimental em busca de leis, mas como uma ciência interpretativa, à procura do significado. É justamente uma explicação que eu procuro ao construir expressões sociais enigmáticas na superfície. Todavia, essa afirmativa, uma doutrina numa cláusula, requer por si mesma uma explicação.
}

E esta explicação pode ser explicada por Sommer (2018, p. 380), em seu texto alusivo a Raymond Williams (1976), que, após retornar dos campos da II Guerra Mundial, teve sua percepção de cultura reorientada: de um "sistema compartilhado de crenças e práticas, segundo os cientistas sociais, para um campo da tentativa e erros criativos, na perspectiva de artistas e humanistas", sugerindo que a concepção de cultura era usada tanto para comemorar padrões sociais quanto para deflagrar esses padrões, por meio de provocações irreverentes. Para Brannen (2011), a cultura é como um fenômeno de nível grupal estabelecido e apoiado no nível individual, por meio de interações consecutivas entre pessoas em determinado contexto organizacional.

\section{O antropologista Mintz (2009, p. 223) entende}

cultura como uma propriedade humana ímpar, baseada em uma forma simbólica, 'relacionada ao tempo', de comunicação, vida social, e a qualidade cumulativa de interação humana, permitindo que as ideias, a tecnologia e a cultura material se "empilhem" no interior dos grupos humanos.

Apropriando-se dessa definição, este artigo justifica a influência das racionalidades e seus paradoxos nas organizações e a necessidade da presença de um gestor cultural que possa facilitar a expansão da cultura, promovendo maior interação humana. Isso faz-se necessário, uma vez que, nesse campo, a perspectiva da cultura atual dilacera a dialética predominante entre a materialidade e imaterialidade, emergindo como atividade definitiva e incompleta na produção e expressão por meio do homem, oriundas de informações e poderes que vêm da própria natureza (EAGLETON, 2003).

As manifestações artísticas culturais são diversas e podem ser caracterizadas como: cinema, teatro, música, dança, livros, pinturas, identidades culturais, sejam nacionais, regionais, étnicas, sexuais, etárias e religiosas, dentre outras, trilhando caminhos contra a 
hegemonia globalizadora (DURAND, 1996; BOTELHO, 2006) e fortalecendo o território (DURAND, 1996; SANTOS, 1999, 2005).

A gestão cultural se propõe a organizar e a sistematizar os processos de trabalho que envolvem o fazer e o saber artístico, em busca de melhores práticas e resultados (CUNHA, 2007; FERREIRA, 2015). O campo da cultura apresenta diferentes demandas, em torno da competitividade e complexidade de atividades que acentuam uma atuação diferenciada, transcendente aos pressupostos da racionalidade instrumental e do capital econômico. Portanto, o objetivo do estudo foi trazer apontamentos e reflexões acerca da gestão cultural a partir das racionalidades e seus paradoxos, vivenciados por um gestor cultural através da autoetnografia. Foi aplicada como estratégia metodológica a abordagem qualitativa e autoetnográfica.

A etnografia é um método de pesquisa que busca descrever fenômenos culturais. É formada por dois elementos básicos: o trabalho de campo (observação participante) e a cultura (meio eficaz para a obtenção de autorreflexão sobre fenômenos culturais encontrados no nível micro). Os estudos etnográficos em profundidade, como os de Whyte (1943), Gouldner (1954) e Dalttífi (1959) são clássicos no campo da Sociologia. No campo dos estudos organizacionais, Van Maanen (1975), Weick (1993), Perlow (1997) e Kunda (2006) geram fortes construções que avançam na teoria e servem de base para testes de teoria dedutiva (BRANNEN, 2011).

A autoetnografia (KOCK; GODOI; LENZI, 2012; HACKEY; HACKEY, 2015; SANTOS; DAVEL, 2015; DAVEL; OLIVEIRA, 2018) corresponde a um gênero da etnografia que suporta maior aprofundamento da pesquisa com a participação do pesquisador, por meio de sua experiência pessoal com a situação em estudo. Esse método permite a obtenção de informações com elevado grau de reflexão, significação e perspicácia.

A autoetnografia é justificada nesse estudo devido ser pouco utilizada na administração, mas aplicada nas diversas áreas das ciências sociais, o que difere da etnografia. Por isso essa produção acadêmica sobre gestão cultural no campo da Administração, reforçando a necessidade de investimento em produções acadêmicas nesta área. Além disso, o cenário político e o desmantelamento do Ministério da Cultura em 2019 reforçam a importância de se trazer o tema da Gestão Cultural, cada vez mais, para o foco das discussões acadêmicas. Dessa forma, a expertise da coautora em quase 20 anos de atuação na área desse estudo, na esfera privada, é uma contribuição para os futuros gestores culturais, além de trazer esse método para a esfera da Administração, sendo uma das contribuições apontar as complexidades e ambivalências no campo da cultura e sua importância nos territórios periféricos.

\section{REFERENCIAL TEÓRICO}

\subsection{RACIONALIDADES E SEUS PARADOXOS}

A evolução das teorias organizacionais evidencia os aspectos de gestão desde a divisão do trabalho, a centralidade nas máquinas, nos processos, até a valorização do homem e do ambiente. Os aspectos da estrutura organizacional tornam-se relevantes para a efetividade operacional e de relações entre seus atores, como os meios na consecução dos fins propostos em suas atividades. Um desses aspectos diz respeito à racionalidade que é encontrada nos estudos da burocracia, controle e gestão social de Weber, Guerreiro Ramos, Habermas, Deleuze, Fernando Tenório, Antônio Carneiro e Maurício Serva. 
As teorias organizacionais têm dificuldade em conciliar o crescente determinismo da racionalidade funcional com a necessidade de emancipação humana (CARNEIRO, 1995). Por muito tempo, a identidade e o trabalho não se dissociavam, criando uma ambivalência, e isso dava sentido à vida das pessoas (BENDASSOLI, 2010). Os estudos organizacionais, de outra forma, não priorizaram áreas importantes relacionadas às dimensões cognitiva, psíquica, afetiva e de identidade (CHANLAT, 1993), áreas fundamentais no contexto da Gestão Cultural.

A sociedade pós-industrial marcou uma transformação do sujeito e sua relação com o trabalho, valorizando o imaterial, que tem o conhecimento, a comunicação e a cooperação como base (SANSON, 2009). O valor do trabalho está mais atrelado àquilo que é próprio do sujeito trabalhador, em suas capacidades e qualidades individuais, de forma mais personalizada, demandando racionalidades que vão além da mera instrumentalização.

A racionalidade para Ramos (1981) pode ser instrumental e substantiva. A instrumental é típica do positivismo e busca a dominação da natureza para fins lucrativos, submetendo a ciência, a técnica e a própria produção cultural ao capital (RAMOS, 1981). Dessa forma, existe uma tentativa de dominação do ser humano na execução de suas atividades, o que culmina na limitação da criatividade. Nesta pesquisa, entende-se que as teorias convencionais da organização reforçam o paradigma da racionalidade funcional. De outro modo, o "indivíduo não cessa de passar de um espaço fechado a outro" (DELEUZE, 1992, p. 2019) e cada qual, família, escola, trabalho e prisão, com suas leis próprias, promovem o confinamento por excelência, no que são categorizadas como "as sociedades de controle" (DELEUZE, 1992, p. 222).

Outra racionalidade tratada por Ramos é a substantiva (valor), que deve ter ação sobre as atividades humanas em busca da promoção e do desenvolvimento das potencialidades (RAMOS, 1981). Diversos autores brasileiros criticam e denunciam a razão instrumental opondo a esse conceito a racionalidade substantiva, mas não demonstram claramente, por meio de exemplos de organizações reais, como se concretiza a razão substantiva na tomada de decisões, na divisão do trabalho, no controle, no estabelecimento de normas, na comunicação e em outras variáveis tipicamente administrativas (SERVA, 1997, p. 20).

É nesse contexto organizacional complexo que vem se desenvolvendo, mais especialmente nas duas últimas décadas, a profissionalização na gestão cultural. $\mathrm{O}$ aumento dos recursos financeiros destinados à cultura tem demandado uma maior sistematização dos processos. Corá (2016) ressalta que o artista tem se transformado paulatinamente em empreendedor, entretanto, existe grande dificuldade nos domínios técnicos da racionalidade instrumental, aplicada às demandas e gargalos do campo da cultura. "O maior problema para quem atua na cultura e na arte é ter planejadores. Isto, porque os projetos de cultura são normalmente financiados para períodos de um ano, o que inviabiliza planejamentos em longo prazo." (CORÁ, 2016 p. 84).

\subsection{RACIONALIDADES NA GESTÃO CULTURAL}

No campo da cultura, a racionalidade instrumental ou funcional é extremamente demandada na mediação entre as relações com o Estado e os gestores empresariais, no que tange à execução de planejamento de projetos afetos às leis de incentivo. O Estado exerce o biopoder que se concentra em controlar, administrar e determinar o corpo da população, o corpo social, sendo uma autoridade soberana que impõe a ordem (SANSON, 2009), por meio de diversos manuais, leis, formulários e instruções normativas, que são instrumentos para orientar essa relação profissional, dentro dos aspectos da burocracia. 
Após a etapa de criação do projeto, que demanda abstração e criatividade, seguemse etapas burocráticas, onde a divisão do trabalho é algo imperativo que dialoga com a prática administrativa, dentro da gestão cultural. Nessa fase, a racionalidade substantiva em detrimento de uma relação que prevaleça sobre a ação racional e sua preocupação excessiva, em relação aos fins, é mais indicada (TENÓRIO, 1990). Entretanto, a distribuição do trabalho não há de ser necessariamente instrumental ou substantiva, uma vez que pode ocorrer a partir da mediação proposta pela teoria da ação comunicativa (TENÓRIO, 1990), por meio do diálogo entre os agentes sociais, de forma colaborativa. A subjetividade do trabalhador passa então a ser um dos principais recursos na lógica organizativa do trabalho (REBECHI, 2016).

Outra questão na gestão cultural refere-se à ambiguidade entre o tempo do não trabalho com o tempo do trabalho, ocorrendo uma mudança na relação do sujeito com a produção e o seu próprio tempo (SANSON, 2009). Por se tratar de um trabalho imaterial, o tempo do trabalho não necessita ser medido, permitindo ao gestor a escolha do seu modo de produção, dentro de variações em sua rotina.

Isso direciona Ramos (1972) no conceito de: "homem organizacional", representado por dois tipos de homens: o "homem operacional" e o "homem reativo". O primeiro é o típico condicionado por métodos tayloristas de organização do trabalho, como recompensas e punições; e o segundo, por métodos integracionistas que buscam estimular reações positivas e advêm da escola das relações humanas e comportamentalista (PAES DE PAULA, 2007, p. 175).

No campo da cultura, as racionalidades ora se complementam, ora se opõem em conflitos e tensões nas relações de poder que se se estabelecem na disputa do acesso aos capitais. Portanto, a existência das ambivalências no campo da cultura e no exercício da função de gestor decorre do imperativo do gerencialismo, (CHANLAT, 2000; REED, 1997) em algumas atividades, recorrente nos paradoxos da racionalidade em um país como o Brasil.

\subsection{GERENCIALISMO NA GESTÃO CULTURAL}

Na sociedade capitalista, o principal ator era a classe trabalhadora, representada por um sujeito com características claras: aplicado, obediente, racional e previsível. Na sociedade do trabalho, ser livre significava construir uma relação ativa, útil e harmoniosa com o mundo. Sob a ética do trabalho, o indivíduo deve postergar os prazeres e educar seus filhos para o labor, sendo que o bom indivíduo é automaticamente o bom trabalhador (BENDASSOLI, 2010).

O trabalho da gestão cultural rompe com a concepção gerencialista da sociedade fordista do capitalismo industrial, onde o trabalho se fazia na reprodução, de forma moldada e dentro de padrões organizados e estruturados (SANSON, 2009). No fordismo, as rotinas eram repetitivas e havia a preconização da relação homem-máquina, de forma racionalizada, por procedimentos que manifestavam uma interação mecanicista. A relação com a produção não permitia uma interação colaborativa (HELOANI, 2007).

Segundo Melo (2000), a função gerencial apresenta distintas fases segundo o contexto social, tecnológico e político, sinalizando uma evolução de um modelo de gestão considerado mais apropriado às organizações contemporâneas. Inclui-se, nesse espaço, a gestão cultural. Esse autor classificou a função em conformidade com o nível de desenvolvimento de cada organização.

Na primeira fase, o gerente esquece o papel de burocrata e busca o conhecimento para ser gerenciador de pessoas e de processos. Na segunda, inclui-se a concepção da modernização da função gerencial, pela qual o gestor percebe que é preciso mudanças na 
forma de se trabalhar e inicia o entendimento do todo da organização, em busca de eficiência e desempenho dos atores. A terceira fase tem como destaque a função gerencial realizada em parceria com os subordinados e com a organização.

Na quarta fase, a ênfase é a função gerencial compartilhada e nesse cenário de gestão há uma mudança da perspectiva da ação gerencial em relação à função do gerente, incluindo no processo, junto à equipe, práticas de empowerment de pessoas. Dessa forma, surgem as novas concepções do exercício do poder no contexto organizacional, o que deve ser considerado para a efetiva atuação na gestão cultural (MELO, 2000). Nessa fase, há a necessidade de uma estrutura organizacional para atender a consecução de seus objetivos.

Com base nos estudos de Enriquez (1997, p.19), são apresentados três tipos de estruturas: carismática, burocrática e cooperativa, que tem uma vertente democrática e outra tecnocrática, originando a estrutura estratégica de gestão participativa. Na gestão cultural, tem-se a gestão participativa como uma forma mais comum de atuação, haja vista os multiprocessos de gestão identificados teoricamente para a racionalidade substantiva e instrumental.

A gestão cultural tem na gestão estratégica participativa uma atuação centrada não na dominação, mas verdadeiramente aberta sem coerção com base em resultados, priorizando a criatividade. Quanto ao grau de participação, a gestão cultural precisa ser controlada para atingir os seus fins. Todavia, deve haver flexibilidade em seus processos nos quais o sujeito necessita de seus atributos e instintos internos, como por exemplo, a criação da arte e a composição musical, entre outras manifestações (BOTELHO, 2006).

A estrutura da gestão cultural está baseada com ênfase nas características da racionalidade substantiva, ampliada pelo fator criatividade e por atributos de controles operacionais da racionalidade instrumental, o que proporciona na gestão integrada os melhores resultados. A atividade requer que o trabalhador tenha habilidades de ser comunicativo, participativo, polivalente, flexível e capaz de realizar multitarefas, de forma que o seu conhecimento enriqueça o processo produtivo e torne a comunicação com os outros um recurso permanente (SANSON, 2009).

Por isso, a profissionalização na gestão cultural teve como modelo as organizações burocráticas, baseadas numa premissa de previsibilidade do comportamento dos indivíduos. Entretanto, como o campo da cultura apresenta pouca previsibilidade, em um ambiente ambivalente, torna-se essencial um gestor com habilidades múltiplas, que consiga atuar em consonância com transformações demandadas pelas mudanças nas bases do trabalho nos últimos anos, tais como: falta de trabalho para todos; mudanças nos tipos de ocupação; incremento tecnológico; reengenharias; razões socioculturais e outras (CUNHA, 2007; BENDASSOLI, 2010). A gestão dos capitais, por fim, envolverá a habilidade do gestor para conversão de determinado capital em outro, como forma de continuidade e valorização da atividade cultural.

\subsection{GESTÃO CULTURAL E AMBIVALÊNCIAS DO PERFIL PROFISSIONAL NO CAMPO DA CULTURA}

A gestão cultural envolve uma complexidade de fatores que tem seu início nas distintas organizações de atuação do gestor dessa área. Esse profissional pode desenvolver suas atividades com carreira nas esferas: pública, privada e social. Tais instâncias possuem estruturas organizacionais peculiares para o gerenciamento da gestão cultural.

O trabalho do gestor cultural, embora ainda distinto, possui uma configuração organizacional mais próxima do toyotismo que traz como principais eixos de mudanças as etapas de trabalho como: processo de produção, fluxos, logística, mobilização de coletivos de 
trabalho e os princípios orientadores de atividade de trabalho, relacionados à flexibilidade, coordenação, integração e polivalência (REBECHI, 2016, p. 105).

Contrariando esse modelo, a atuação do gestor cultural demanda uma ação mais autônoma, com abertura para novos modelos e criação de mercados. Esse gestor está muito longe de ser um profissional obediente, racional e previsível. A sua atividade demanda criatividade, autonomia, inovação e superação dos obstáculos impostos. Essa atuação é muito diferente do que se esperava do trabalhador na era fordista, o qual atuava em silêncio e sem interação. Ao gestor cultural cabe a comunicação e a criação de redes, uma variante mais adequada ao capitalismo cognitivo, em sua versão pós-industrial (SANSON, 2009).

$\mathrm{O}$ trabalho gerencial está embasado em três dimensões fundamentais: pensamento, pessoas e ação (MINTZBERG, 2004), o que, no campo da cultura, podemos traduzir livremente como: ideias, pessoas e produção. Como ideias, podemos definir o processo de concepção artística ou criação. O profissional dessa área requer conhecimentos diversificados como formação humanística, sensibilidade estética, habilidade política e conhecimentos de economia, controladoria e administração. Além desses, é preciso ter uma centralidade na criatividade para suprir as possibilidades e diversidade mercadológica, que retrata o cenário real das políticas e atividades culturais na era contemporânea brasileira.

Para entender as atribuições do gestor cultural, recorre-se a Paes de Paula (2007) que denominou como o "homem parentético" o que faz opção pela autonomia e consciência crítica, fora dos padrões dos tipos operacional e reativo. A autora enfatiza quatro tipos de ação social na mesma abordagem de Weber "(...): a racional no tocante aos fins, a racional no tocante aos valores, a afetiva e a tradicional." (PAES DE PAULA, 2007, p. 176).

A racionalidade funcional tem relação com a ética e a responsabilidade, ao passo que a racionalidade substantiva está relacionada à convicção (TENÓRIO, 1990). Em relação ao tipo afetivo, Paes de Paula (2007) ressalta que esse é guiado por estados emotivos, e no caso do tipo tradicional é guiado pelos costumes, sendo ambos de caráter subjetivo.

Tomando como base as definições de racionalidades apontadas por Guerreiro Ramos e Tenório, foi possível a segmentação das atividades do gestor cultural, a partir das etapas que envolvem a realização de um projeto cultural (Quadro 1).

\begin{tabular}{|c|c|c|}
\hline Etapa & Descrição & Racionalidades \\
\hline \multirow{3}{*}{ Pré-produção } & Criação e idealização & - \\
\hline & $\begin{array}{l}\text { Elaboração e aprovação do projeto junto aos órgãos } \\
\text { públicos }\end{array}$ & Instrumental Funcional \\
\hline & Captação dos recursos junto aos incentivadores & Substantiva e Comunicativa \\
\hline \multirow{3}{*}{ Produção } & $\begin{array}{l}\text { Construção de uma rede de fornecedores e seleção de } \\
\text { equipe de produção }\end{array}$ & Comunicativa \\
\hline & Relacionamento com os públicos pretendidos & Comunicativa \\
\hline & $\begin{array}{l}\text { Realização, acompanhamento e aferição do impacto dos } \\
\text { resultados }\end{array}$ & $\begin{array}{l}\text { Instrumental, Substantiva e } \\
\text { comunicativa }\end{array}$ \\
\hline Pós-produção & $\begin{array}{l}\text { Prestação de contas junto aos órgãos públicos e aos } \\
\text { incentivadores }\end{array}$ & Instrumental Funcional \\
\hline
\end{tabular}

Fonte: elaborado pelos autores.

A gestão na cultura traz à tona as ambiguidades e complexidades que a função gerencial, por si só, não dá conta de atender, como: acolher as demandas das legislações de incentivo versus pressão dos artistas ou criadores; tornar sua entidade ou organização mais

RGO - Revista Gestão Organizacional, Chapecó, v. 13, n. 3, p. 119-139, set./dez. 2020. 
eficiente e eficaz, mais racionalizada versus criar novos projetos; atender aos apelos artísticos (desejos e pulsões) versus ter de comportar-se de forma racional, com formalização de procedimentos e prestação de contas; e ser criativo versus ser limitado pela burocracia das leis de incentivo.

Assim, pressupõe-se que o gestor cultural seja dotado de uma racionalidade gerencial, que dê conta de resolver todos os problemas relacionados com a dinâmica da atividade e função, em especial, na instância do Estado que, cada vez mais, está subjugado ao mercado de capitais, figurando mais como um dispositivo de controle, repressão e exclusão, a serviço do sistema capitalista. (SOARES, 2016). Ao mesmo tempo, o trabalho do gestor na cultura demanda também a comunicação aberta, estratégias participativas sem dominação do indivíduo e normas coletivas para direcionamento das atividades com pilares em capital econômico, cultural e simbólico. Em suma, o que se espera da gestão na cultura é lançar mão das diferentes racionalidades em busca da efetividade na atuação.

Ao gestor cultural também cabe a função de gerir os investimentos das empresas e de pessoas físicas na execução dos projetos por elas beneficiados, por meio das leis de benefício fiscal brasileiras. Entretanto, esses projetos são oriundos de ideias que emergem da criatividade e da capacidade artística do próprio gestor, de um artista ou grupo cultural. Há aqui um paradoxo entre uma atividade permeada pela racionalidade e pela ordem, mas que ao mesmo tempo é mediada pela criatividade e pelo acaso (PORÉM; VERAS, 2016). O planejamento é um passo fundamental na atividade de gestão dos ativos da cultura, devendo ser flexível ao se considerar que há uma rede de profissionais que vão atuar desde a criação até a concepção dos projetos culturais (CORÁ, 2016).

O local, a rotina e a atividade do gestor cultural, em alguns casos, tende a ser mais flexível do que a rotina do trabalhador convencional. $O$ gestor cultural, que atua no campo social, pode exercer sua função fora do ambiente formal de uma organização, em espaço de coworking ou home office e utilizar também ferramentas menos formais para comunicação, tais como o WhatsApp e o Facebook.

Entretanto, é importante pensar essa "flexibilidade" também pelo seu viés crítico, sugerido por Rodrigues (2011), que entende o ser flexível como a ideologia criada pelo capitalismo que nos aprisiona ainda mais. A dominação anterior se localizava num lugar - a fábrica - e atualmente configura-se na mais rigorosa das exigências: a da flexibilidade. Nesse sentido, a demanda por uma maior necessidade de adaptação imediata ao novo, aos curtos prazos, às jornadas longas, faz com que o gestor cultural aparente estar sempre disponível, e isso, muitas vezes, não se traduz em remuneração.

$\mathrm{O}$ gestor cultural que consegue congregar as diferentes racionalidades à criatividade tem mais potencial de sucesso no planejamento de suas ações. Dessa forma, tem múltiplas racionalidades associadas à razão, emoção e intuição, sem deixar de considerar apenas um cálculo objetivo e previsível (GOMES et. al., 2016). Portanto, o gestor cultural precisa ter ou desenvolver competências culturais.

\section{METODOLOGIA}

Foi aplicada como estratégia metodológica a abordagem qualitativa e adotada a autoetnografia. A pesquisa qualitativa procurou como estudo pessoas ou grupos de pessoas que apresentavam multiplicidade de olhares para a realidade social ou psicológica. Por meio da interpretação do modo de agir dessas pessoas ou grupos de pessoas, buscou-se significado sobre a construção da realidade no contexto de ocorrência (MERRIAM, 2002; HANCOCK; OCKLEFORD; WINDRIDGE, 2007). 
A autoetnografia (FORTIN, 2009; KOCK et al., 2012, HACKEY; HACKEY, 2015; SANTOS; DAVEL, 2015; SANTOS; BIANCALANCA, 2017; MAGALHÃES, 2018; DAVEL; OLIVEIRA, 2018) é um método que envolve outros métodos, ou seja, um multimétodo que envolve várias informações associadas, muito aplicado em áreas pouco exploradas e com menos teorização (KOCK et al., 2012). Assim, é importante a imersão interna na expertise da coautoria do estudo.

Segundo Ellis, Adms e Bochner (2011), a autoetnografia é uma abordagem de pesquisa que tem o propósito de descrever e analisar, de forma sistemática, a experiência pessoal, para compreender a experiência cultural. Fundamenta-se na apresentação de uma autoanálise sobre o passado e o futuro, em determinado contexto social e cultural da atividade desenvolvida, constituindo uma autoetnografia baseada na narrativa da experiência pessoal (KOCK et al., 2012).

Para Benetti (2017, p. 152), a autoetnografia é uma metodologia de pesquisa que apresenta amplas possibilidades como:

a) utiliza a experiência pessoal do pesquisador para descrever e criticar crenças
culturais, práticas, e experiências; b) reconhece e valoriza as relações do pesquisador
com os outros; c) utiliza uma profunda e cuidadosa autorreflexão - habitualmente
referida como "reflexividade" - para nomear e interrogar as intersecções entre o eu
e a sociedade, o particular e o geral, o pessoal e o político; d) mostra "pessoas no
processo de descoberta sobre o que fazer, como viver, e o significado de suas lutas";
e) equilibra o rigor intelectual e metodológico, a emoção, e a criatividade; f) busca
por justiça social e por uma vida melhor.

Ellis e Bochner (2000) provocam dizendo que não há nenhuma pessoa melhor para analisar e refletir sobre determinada questão do que a própria pessoa envolvida, devido à experiência de 20 anos vivenciada na área, no caso desse estudo. É importante a introspecção mais completa possível, sem medo de mostrar as fraquezas e os pontos fortes, pois compreendendo a si compreende-se o meio, gerando reflexões para o autor e para o mundo. No processo da autoetnografia, o pesquisador descreve o passado e o futuro de forma seletiva e, ao mesmo, tempo faz análise de sua experiência concatenado com a literatura (ELLIS et al., 2011).

A autoetnografia foi realizada pela coautora desse estudo, a qual atua desde 2001 como gestora cultural, produtora e professora. É casada, mãe e está em processo de doutoramento, portanto, exercendo tripla jornada de trabalho (VIEIRA; AMARAL, 2013). A pesquisadora tem como competências a visão estratégica e sistêmica sobre práticas de sustentabilidade e a habilidade de comunicação e influência, com grande interação em projetos com comunidades, entidades de classe, parceiros culturais, artistas, representantes de governo e com colaboradores internos e externos. Trabalha como gestora cultural em uma empresa do âmbito privado, no ritmo de 40 horas semanais em regime de dedicação integral.

Para delinear este estudo de autoetnografia, foi construído um roteiro para entrevista semiestruturado focalizando quatro aspectos relacionados às ambivalências no passado e presente, em termos de racionalidades na gestão cultural perante as práticas executadas pela gestora cultural. As práticas levantadas foram: 1. Como foi conseguir o primeiro emprego nesta área e quais as ambivalências existentes na época? 2. Quais foram os insucessos e o que teria feito diferente? 3. Como é para a gestão cultural trabalhar com a Lei Rouanet? 4. Descreva os passos do dia a dia de um gestor cultural nos últimos 10 anos e na atualidade. 5 . Mediante a sua experiência pessoal, como você percebe as racionalidades envolvidas na gestão cultural? 


\section{RESULTADOS}

Os dados oriundos da entrevista foram categorizados e consolidados em três práticas. A seguir, encontram-se as narrativas divididas em 4.1, 4.2 e 4.3.

\subsection{O PRIMEIRO EMPREGO COMO GESTORA CULTURAL E AS AMBIVALÊNCIAS DA ÉPOCA}

\subsubsection{0 resgate da memória: da infância à gestora cultural}

Atuo no campo da cultura há quase vinte anos e o considero como a minha aldeia, mas o meu primeiro contato com a arte aconteceu tarde. Sou filha de Helena e Manoel. Helena é a filha mais velha de uma família de onze irmãos. Nascida no interior de Minas Gerais, em uma época em que os filhos eram gerados para ajudar na lavoura, sofreu com o trabalho infantil e construiu seu baixo capital cultural com muito esforço. Estudou até a 4a série e teve muito pouco tempo para qualquer tipo de entretenimento. Profissionalmente, sua vida foi dedicada aos serviços como doméstica e costureira. Manoel, apenas cinco dias mais velho do que Helena, também nasceu no interior de Minas e é o terceiro filho de cinco irmãos. Profissionalmente, Manoel trabalhou como segurança, pedreiro, zelador e porteiro. Seus estudos também foram até a 4a série do primário.

Minha história começa aqui, como a filha primogênita desse casamento. Nasci no Bairro Paulo VI, localizado na periferia de Belo Horizonte, na Regional Nordeste, onde morei até os 27 anos. Minha irmã nasceu três anos depois de mim e tivemos nossa infância e adolescência marcadas pela dificuldade decorrente da limitação de recursos, mas ainda assim uma infância feliz e rodeada de muito afeto.

Além das brincadeiras de criança, a principal fonte de entretenimento era a televisão e os programas infantis da década de 90 , mas quando completei onze anos de idade esse aparelho foi retirado de nossa casa. O motivo foi a religião dos meus pais, que, em nome dos bons costumes e da família, abominavam o conteúdo "mundano" televisivo e era melhor que "uma mocinha" não tivesse acesso a eles. Inicialmente essa mudança abrupta foi bastante sofrida para uma pré-adolescente tímida, com poucos amigos e muitas ideias, cerceadas pelo rigor da religião. A válvula de escape foram os livros e encontrei na literatura uma grande parceira. A fantasia encontrada na literatura ajudou a me manter salva, pois eu podia escapar por ela de uma vida cheia de restrições e inadequações. Nessa época, eu lia uma média de três livros por semana, dos clássicos de Machado de Assis, como "Helena", até a literatura infantojuvenil de sucesso à época, tal como "Crescer é perigoso" de Márcia Kupstas. Assim, um novo universo abriu-se para mim, mais diverso e bastante instigante.

O cinema veio logo em seguida, apresentado por um projeto iniciado na escola municipal onde eu estudava. A professora de Literatura, bastante indignada com o baixo conhecimento da turma sobre cinema, iniciou um projeto de sessão pipoca. Esse foi um grande momento para mim e para a classe, formada por outras crianças com pouco acesso como eu e foi, nessas sessões, que conheci filmes como "O piano" e "A casa dos Espíritos". Nessa fase, eu estudava pela manhã e já trabalhava à tarde. Minhas vivências profissionais, se é que se pode chamar assim, confundem-se com o início da minha pré-adolescência, também por volta dos meus onze anos, quando comecei a executar trabalhos como babá, vendedora de Avon e professora do EJA, que à época era ofertada às senhoras da igreja que eu frequentava.

Foi por volta dos meus dezessete anos que finalmente tive a experiência de entrar em um cinema. Lembro-me bem da minha primeira sessão, quando assisti ao "glorioso" Titanic, no extinto cinema Palladium da rua Rio de Janeiro em Belo Horizonte. Marcaram-me a força 
do som, a beleza das imagens, a espessura das cortinas e o frio do ar condicionado. A televisão continuou abolida na minha casa até que eu completasse 21 anos de idade, quando eu pude comprar, com o meu primeiro salário mínimo, um pequeno aparelho televisor que foi colocado em meu quarto. Nesse período, como "eu já pagava as minhas próprias contas", consegui convencer os meus pais a aceitar o retorno do aparelho de TV à nossa casa.

O amor aos livros e ao cinema levou-me a escolher o curso de Letras na graduação, cursado com muita dificuldade, sendo eu uma das primeiras em uma linhagem familiar que historicamente não valorizava o ensino superior. Desde pequena eu já sabia bem o que eu queria: "ser professora e era o que eu repetia de imediato sempre que me perguntavam sobre a minha futura profissão. E essa foi uma das primeiras mudanças ao longo do meu processo de (des) identidade, o qual denomino afetivamente assim, por acreditar que a minha vida tem sido marcada por um processo de construção e reconstrução, de escolhas e mudanças no percurso dessas escolhas.

\subsubsection{O primeiro emprego com a gestão cultural}

Cursei apenas dois períodos e iniciei um estágio em uma empresa do campo da cultura, como analista de projetos culturais. Por meio desse estágio, tive acesso à minha primeira ópera, assistida no Palácio das Artes. A ocasião me deixou muito feliz, mas bastante constrangida, por não saber muito bem o que vestir ou como me comportar em uma ocasião tão ilustre. Ainda, esse mesmo estágio permitiu-me assistir aos espetáculos de teatro, dança e circo. Nessa empresa descobri que a cultura é um direito garantido pela Constituição brasileira e que existiam leis de incentivo à cultura que deveriam assegurar esse direito a todo cidadão.

O salário recebido por mim nesse estágio tinha como finalidade apenas custear os meus estudos em uma universidade privada. Mas, para completar ainda mais as dificuldades econômicas que atravessaram a minha vida familiar, aos 54 anos, meu pai foi demitido do seu trabalho como segurança, na empresa à qual dedicou mais de 18 anos de sua vida, sem receber qualquer quantia, nem ao menos o salário do mês, pois a empresa havia aberto falência. Assim, no meio do meu curso de graduação, fui obrigada a reduzir quase toda a carga horária na universidade para me tornar "arrimo" de família, até que o meu pai conseguisse de fato se aposentar, seis anos mais tarde. Isso interferiu na minha graduação, que só foi concluída quando eu completei 27 anos de idade.

Não encerrei o curso de Letras, pois ao final do segundo período me interessei pela psicologia e fiz a reopção de curso. Foi ao final da minha graduação no curso de Psicologia, que eu novamente descobri o que de fato eu desejava como carreira: atuar no campo da cultura. Iniciei em seguida uma pós-graduação em Gestão Cultural e, em 2009, abri uma empresa: a "Capital Cultural", a qual captava recursos por meio das leis de incentivo para execução de propostas culturais diversas. Pela Capital Cultural tive oportunidade de criar projetos que deram acesso às crianças e idosos ao cinema pela primeira vez.

Em 2011, continuei meus estudos fazendo um mestrado profissional em Gestão Social e Desenvolvimento Local. Por meio desse trabalho, tive oportunidade de conhecer mais sobre empresas que incentivam o desenvolvimento de comunidades, utilizando as leis de benefício fiscal. Um tempo após finalizar o curso, comecei a questionar a minha atuação no campo da cultura e o que eu fazia na época: captação de recursos para projetos incentivados. Sentiame, nessa época, muito acomodada e confortável com a atividade que eu realizava e foi assim que me saltou a vontade de contribuir mais e de atuar diretamente com comunidades menos amparadas pelas políticas públicas e pelo Estado. Nesse período, mais uma vez, eu abri mão 
de um trabalho bem remunerado, realizado por mais de uma década e me reinventei ao ser convidada a iniciar uma nova atividade em uma fundação empresarial, que atua fortemente em regiões periféricas de Minas Gerais, levando educação, cultura e esporte como mote de transformação social. É nessa Fundação que eu trabalho atualmente, onde há seis anos gerencio a área de projetos sociais incentivados, que atendem a mais de 400 mil pessoas, anualmente, em situação de vulnerabilidade social, por meio de diversas iniciativas.

Como gestora cultural, tenho o privilégio de registrar, cotidianamente, a primeira vivência artística e cultural de diversos indivíduos. Há alguns anos, assisti a uma reportagem com uma pesquisadora que, embora já tenha muitas décadas de profissão, até hoje se emociona quando finaliza um trabalho ou um novo experimento, pois para ela é como se pudesse viver novos "milagres por dia". No meu trabalho, tenho um sentimento parecido, porque são quase duas décadas atuando no campo da cultura, mas continuo ficando emocionada a cada novo projeto que se inicia, com cada novo espectador que tem a oportunidade de viver a sua primeira experiência artística e cultural e em cada nova narrativa, capaz de atravessar pessoas e de levá-las a lugares novos, a novas escolhas e oportunidades.

\subsubsection{ALÉM DOS SUCESSOS, EMOÇÕES, A PRÁTICA DIÁRIA TAMBÉM LEVA A INSUCESSO. SEMPRE DÁ PARA FAZER DIFERENTE!}

O insucesso da atuação no campo da cultura, talvez seja a forma como a cultura é concebida no campo político, pois sempre foi tratada como um tema periférico, fora das principais preocupações e investimentos públicos. Pouco considerada pelo seu potencial de desenvolvimento,

(...) continua aparecendo ainda como um ornamento supérfluo, uma forma de lazer, de entretenimento, o que impede de percebê-la como pensamento, imaginação, criatividade, racionalidade, emoção e como o meio por onde construímos e partilhamos os sentidos de vida (DIAS; COSTA, 2017, p.2).

Pensar que os problemas da cultura se encerram no patamar econômico é limitar o potencial de desenvolvimento de uma sociedade. É nesse sentido que argumento que a cultura ocupa um lugar periférico nas discussões sobre desenvolvimento e sobre criação de políticas públicas.

A insegurança político-econômica na cultura encerra as atividades em construção de projetos e muito raramente em planos de trabalho de longo prazo “(...). Enquanto a importância das questões econômicas é autoevidente, a questão da cultura, para a maioria das autoridades políticas, tende a parecer ornamental ou simplesmente enfadonha." (LIMA, 2004, p. 13).

Os artistas e gestores que se encontram mais preparados no campo da cultura têm mais facilidade para acessar os recursos distribuídos, seja pelo conhecimento mobilizado para elaborar um projeto, interpretar um edital, ou acionar um patrocinador. Essa situação faz surgir um mal-estar que desencadeia diversas lutas simbólicas no campo da cultura, pela dificuldade de se adequar às exigências que emanam da burocracia nessa área.

\subsection{A GESTÃO CULTURAL COM A LEI ROUANET}

As políticas públicas para a cultura vêm, historicamente, operando na busca pela democratização do acesso aos bens e aos direitos culturais. No decorrer dos últimos quase trinta anos, o cenário cultural brasileiro fomentou a realização de diversos projetos artísticos que preconizam a inserção social. Os anos 90 foram um marco para o desenvolvimento de um 
Plano Nacional de Cultura com ações voltadas ao atendimento de diversos desafios, dentre eles, dar acesso às produções artísticas e promover a inclusão por meio da arte.

O Governo Federal, através do Programa Nacional de Apoio à Cultura (Pronac), em uma iniciativa do Ministério da Cultura, implementou mecanismos da renúncia fiscal (Mecenato) e do FNC (Fundo Nacional de Cultura), ambos integrados à Lei Federal 8.313/91 (Lei Rouanet). Esse mecanismo tem como propósito capturar e distribuir recursos para fomentar a produção, a distribuição e o acesso descentralizado aos bens culturais, preservar o patrimônio nacional (material e imaterial) e promover a difusão da cultura brasileira e sua diversidade. O mecanismo opera por meio de parcerias intersetoriais entre governo, iniciativa privada e sociedade civil.

Os recursos incentivados, dedicados às ações desenvolvidas no campo da cultura, entre outras coisas, têm o propósito de atuar como um processo dinamizador da sociedade, com vistas a melhorar a qualidade de vida, contribuir com o acesso e aumento do capital cultural, apoiar o surgimento de novas formas e linguagens artísticas, além de promover a distribuição de riqueza econômica, cultural e social. O extinto Ministério da Cultura, principal vetor responsável pelo desenvolvimento no campo da cultura, atuou fortemente nos últimos anos em prol da inclusão. Muito embora não tenha envidado esforços, a equipe técnica, que hoje ocupa a pasta da Secretaria Especial de Cultura, segue travando uma luta na distribuição dos recursos de forma paritária, de modo que seja promovido o acesso ao capital cultural para os sujeitos que ainda não têm acessibilidade aos projetos artísticos e culturais, em especial aqueles residentes nas periferias brasileiras.

Em 2016, o volume de incentivos fiscais, em âmbito federal, repassados apenas pelas empresas incentivadoras, por meio da Lei Rouanet, foi de $\mathrm{R} \$ 1.110 .522 .508,84$ (um bilhão, cento e dez milhões, quinhentos e vinte e dois mil, quinhentos e oito reais e oitenta e quatro centavos), enquanto que o Fundo Nacional de Cultura destinou $\mathrm{R} \$$ 936.717.279,00 (novecentos e trinta seis milhões, setecentos e dezessete mil e duzentos e setenta e nove reais) aos projetos culturais. Até o ano de 1995, chegava-se apenas à marca de 700 milhões de reais (DURAND, 2000), em volume de repasses. Em 2018, no último ano de atividade do Ministério da Cultura, a Lei Rouanet, recebeu 3.197 projetos culturais, que juntos captaram $\mathrm{R} \$ 1,288$ bilhão em recursos incentivados de pessoas físicas e jurídicas, $\mathrm{R} \$ 100$ milhões a mais em comparação com 2017. O valor total da captação em 2018 superou os números do ano de 2016 ( $R \$ 1,149$ bilhão/2.837 projetos) e 2017 ( $R \$ 1,188$ bilhão/2.870 projetos), sendo esse o terceiro maior valor captado nos 27 anos da Lei Rouanet, perdendo apenas para os anos de 2011 ( $R \$ 1,326$ bilhão) e 2014 ( $R \$ 1,336$ bilhão).

O período de recessão, vivido pelo país nos últimos anos, também foi um fator preponderante para o dilema da cultura. No auge da crise no ano de 2016, um movimento iniciado nas redes sociais questionou veementemente a motivação de se manter o Ministério da Cultura, em detrimento ao atendimento das necessidades de outras áreas, como a da Saúde e da Educação. A desmobilização, de fato, do Ministério da Cultura ocorreu em 2019, no atual governo. Essa foi uma promessa de campanha, em enfrentamento à oposição realizada por artistas ao longo do ano de 2018, que fomentaram um movimento nas redes sociais do país, onde clamavam usando o bordão: "Ele Não". Diversas atrizes protagonizaram a campanha que chegou a liderar como o assunto mais comentado nas redes sociais que ficou entre os top trends do Twiter.

Na revisão ministerial, o Ministério da Cultura passou a ser uma secretaria de assuntos especiais, dentro do Ministério da Cidadania, comandada pelo ministro Osmar Terra, que absorveu também a pasta do esporte e do desenvolvimento social. Como secretário, foi 
nomeado um técnico da área da cultura, o gaúcho Henrique Medeiros Pires, que, desde 2016, chefiava o gabinete do Ministério do Desenvolvimento Social. Pires foi demitido da Secretaria Especial da Cultura em agosto de 2019 e no seu lugar assumiu José Paulo Soares Martins, exSecretário Adjunto da Cultura.

A demissão do secretário decorre do não alinhamento de suas ideias com as do atual presidente. $\mathrm{O}$ governo promoveu um cenário de mudanças na Lei Rouanet e na pasta da cultura. A mudança da lei se deu em defesa de que os mecanismos de financiamento da cultura deveriam ser "revisitados", de modo que houvesse uma maior inclusão e o estímulo à redução da desigualdade na distribuição dos produtos.

No mês de novembro de 2019, o governo fez a transferência da pasta da Cultura para o Ministério do Turismo. A expectativa seria que o Ministério da Cidadania seria futuramente fundido ao do dos Direitos Humanos. No entanto, em manifestações nas redes sociais, artistas suspiraram aliviados, pois para eles seria melhor que a Cultura estivesse sob a tutela de um determinado ministro, do que debaixo de um ministério chefiado por uma ministra que tem uma visão mais conservadora, tradicional e arraigada ao protestantismo.

A desidratação do campo da cultura foi sentida ao longo do ano de 2019, por artistas, produtores e espaços culturais, devido à redução de recursos em empresas do governo. Diversos editais, historicamente realizados, foram suspensos, e, em paralelo, a Comissão de Cultura da Câmara dos Deputados aprovou, também no mês de novembro, que eventos religiosos e promovidos por igrejas sejam enquadrados como eventos culturais, podendo assim receber benefícios por meio da Lei Rouanet. Em suma, os poucos recursos para o campo da cultura, passaram a ser disputados também pelos grupos evangélicos.

\subsection{AS RACIONALIDADES ENVOLVIDAS NA GESTÃO CULTURAL}

Na Antiguidade Clássica e nas Idades Média e Moderna, já existiam formas de trabalho associadas à produção, distribuição e ao consumo no campo da cultura. A profissão de gestor cultural é uma área relativamente nova e teve sua ascensão no século XXI (CUNHA, 2007). Desde então, o Gestor Cultural tem ganhado espaço, destacando-se no suporte das exigências e burocracias das leis de incentivo.

No campo da cultura, o gestor é o profissional responsável pelo gerenciamento da execução de todas as atividades, produtos e serviços produzidos, mas além do gestor cultural, outros profissionais também fazem parte da extensa cadeia da cultura como: curadores, produtores, atores, criadores, diretores, pesquisadores, técnicos, dentre outros.

$O$ gestor cultural que consegue congregar as diferentes racionalidades à criatividade tem mais potencial de sucesso no planejamento de suas ações. A gestão cultural propõe-se a organizar e a sistematizar os processos que envolvem o fazer e o saber artístico, em busca de melhores práticas e resultados. O campo da cultura apresenta diferentes demandas, em torno da competitividade e complexidade de atividades que acentuam uma atuação diferenciada, transcendente aos pressupostos da racionalidade instrumental e do capital econômico.

No campo da cultura há uma grande diversidade de profissionais oriundos de áreas afins que vem ingressando, ao longo dos anos, no setor cultural. Corá (2016) afirma que o artista tem se transformado pouco a pouco em empreendedor. Entretanto, existe grande dificuldade nos domínios técnicos da racionalidade instrumental, aplicada às demandas e gargalos do campo da cultura: "O maior problema para quem atua na cultura e na arte é ter planejadores. Isto porque os projetos de cultura são normalmente financiados para períodos de um ano, o que inviabiliza planejamentos em longo prazo." (CORÁ, 2016 p.84). 
Pensar a cultura como gestão significa: entender que ela é ingrediente indispensável dessa concepção; reconhecer que não é possível desenvolver modelos de gerenciamento flexíveis e participativos; e que é preciso descentralização administrativa, articulações sociais, institucionais e controle social, desconsiderando o substrato cultural sobre o qual se apoiam esses processos.

O gestor cultural tem também desafios colocados pela necessidade de fazer convergir desenvolvimento e cultura, promover a distribuição e o acesso aos bens culturais. $O$ gestor cultural precisa assumir e tomar consciência da importância de seu papel social e de suas interferências para a vida comum, na perspectiva do desenvolvimento humano, visualizando na diversidade cultural uma dinâmica complexa, para além do gerencialismo. O gestor cultural tem papel fundamental na articulação entre diversos atores como o poder público, a comunidade local, artistas e o público consumidor cultural. Nesse sentido é crucial que esse profissional aceite e valorize as ambivalências compreendidas no seu papel.

\subsubsection{Quem executa e faz a prestação de contas do investimento em cultura}

O Programa Nacional de Apoio à Cultura operacionaliza-se por meio de relações entre o governo federal, a iniciativa privada e os agentes culturais. Quanto ao primeiro, por meio da Secretaria da Cultura, cabe aprovar o orçamento anual de cada mecanismo, construir políticas públicas para o segmento e avaliar as propostas ou projetos que tornam factíveis essas políticas. No caso da iniciativa privada, engloba as pessoas jurídicas e físicas competindo a elas participar no processo de seleção de projetos e de repasse dos recursos de seus impostos devidos aos aprovados pela Secretaria da Cultura. Por fim, cabe aos agentes culturais a responsabilidade da criação dos projetos e da gestão dos recursos repassados pelas empresas, bem como da prestação de contas da aplicação desses recursos para a Secretaria da Cultura.

Ao longo da minha trajetória profissional, já estive do lado de quem produz eventos e projetos, mas agora estou do lado de quem patrocina: a iniciativa privada. A prestação de contas é de responsabilidade de quem realiza o projeto: o produtor e esse é um processo bastante burocrático e sofrido para a maioria dos trabalhadores da cultura, que operam por meio das leis de incentivo. Isso ocorre devido à grande exigência das leis e à intensa demora na análise das prestações de contas, que se avolumam dentro da Secretaria de Cultura. Um exemplo disso é que no corrente ano (2019) recebi um contato da secretaria solicitando documentação de um processo de prestação de contas entregue em 2011. O risco para o produtor é de que, passados tantos anos, ele tenha que devolver ao erário os recursos que forem considerados como aplicados indevidamente.

Do ponto de vista de quem patrocina: a empresa, não há o risco de devolução dos recursos e sim apenas o risco de não ter as expectativas e contrapartidas negociadas previamente. Nesse sentido, é importante traçar os resultados que a empresa busca por meio de seus investimentos. Os incentivos fiscais poderão ser quantificados e apresentar melhores resultados se estes forem planejados criteriosamente e buscarem metas traçadas pela organização, juntamente com os proponentes culturais. Como reciprocidade, a empresa poderá ainda obter alguns resultados. Dentre as opções, destacam-se: retorno institucional, merchandising de produtos, relacionamentos e ações voltadas para o público interno da empresa, tais como: a distribuição de cortesias, descontos, visitas monitoradas etc.

$\mathrm{Na}$ organização onde trabalho atualmente, são aplicados, por ano, cerca de 15 milhões de reais em mais de 70 projetos, que atendem 49 comunidades e beneficiam mais de 300 mil pessoas. Essa atividade é desenvolvida por uma equipe de três pessoas. 


\section{CONSIDERAÇÕES FINAIS}

O objetivo deste estudo foi trazer apontamentos e reflexões sobre a gestão cultural a partir das racionalidades e seus paradoxos, vivenciados por um gestor cultural através da autoetnografia. Na gestão cultural, há prevalência dos atributos da racionalidade substantiva, entretanto, não se pode negar a importância das racionalidades comunicativa e instrumental, para atingimento dos objetivos propostos a execução das atividades demandas pelo campo da cultura aos gestores que atuam nesse campo.

A gestão cultural tem como fonte motriz o capital cultural que deve ser convertido nas demais fontes. Esse tipo de gestão requer múltiplas características para o seu gerenciamento, ao passo que, para uma estrutura unívoca nesse campo, há necessidade de outros estudos empíricos para consubstanciar a teoria da racionalidade substantiva e a gestão de capitais. Essa pode ser uma lacuna de pesquisa para futuros trabalhos no campo da gestão cultural.

O estudo aponta a importância da cultura para o exercício da cidadania, como direito assegurado pela constituição brasileira, além de ressaltar as ambivalências a que o gestor do campo da cultura está submetido e, simultaneamente, enfatiza como a memória é substancial para a utilização desta metodologia.

Outros apontamentos do estudo são a trajetória de vida da coautora, uma vez que o processo de acesso à cultura é, historicamente, negligenciado para as pessoas em territórios periféricos, onde a cultura pode vir a promover a redução da desigualdade social ao subsidiar o acesso ao capital cultural, que por sua vez pode trazer como possibilidade a mobilização de outros capitais.

A importância de um gestor orgânico, seja nas esferas federal, estadual e municipal e nas organizações, também é uma oportunidade tratada por esse trabalho. É imprescindível que os gestores que atuam no campo da cultura detenham experiências e conhecimentos sobre a legislação, execução e a prestação de contas, além de um olhar holístico, sem preconceitos, que permita valorizar os diversos saberes e fazeres que compõe a cultura brasileira. É urgente que o acesso a arte e a cultura venha transgredir os guetos da classe alta e média alta e perpassar os territórios periféricos. E, essa mudança só será possível a partir da construção de Políticas Públicas mais aderentes as necessidades e peculiaridades das pessoas que habitam esses territórios.

Outro apontamento para futuras pesquisas é a compreensão do fenômeno do acesso à cultura como potencial para a mobilidade social e para a transformação pessoal. Sugeremse pesquisas que apresentem reflexões sobre a situação atual do campo da cultura com os diversos públicos, os hegemônicos e os periféricos, a partir da análise se o acesso a arte e a cultura tem ocorrido de forma democrática como de fato assegura a nossa constituição.

Trata-se, também, de um campo minado, em razão de a gestão política e administrativa dar importância ou não a determinadas áreas, como é o caso do questionamento da importância da Lei Rouanet, e também do direcionamento de seus recursos, sendo essa lei criada para dar aumento da acessibilidade a bens culturais aos excluídos, promovendo a gestão financeira e accountability para a sociedade na área da cultura. Assim sendo, enfatiza-se a importância de que, por meio das narrativas e do uso de indicadores, esses trabalhos de pesquisa possam facilitar o entendimento do público em geral, gerando informações que abranjam impactos que vão desde o aspecto econômico ao social, identificando a importância da arte e da cultura para o desenvolvimento dos mais diversos territórios e comunidades. 


\section{REFERÊNCIAS}

BENDASSOLI, P. F. O culto da performance como resposta à crise da ontologia do trabalho. In: EHRENBERG, A. O Culto da Performance - da aventura empreendedora à depressão nervosa. Aparecida: Idéias \& Letras, 2010, p. 209-239.

BENETTI, A. A autoetnografia como método de investigação artística sobre a expressividade na performance pianística. Opus, Aveiro, v. 23, n. 1, p. 147-165, abr. 2017. DOI: http://dx.doi.org/10.20504/opus2017a2306.

BOTELHO, I. Para uma discussão sobre política e gestão cultural. São Paulo, 2006. p.45-60. Disponível em: http://www.cultura.gov.br/upload/Projeto_Oficinas_Miolo_1156970790.pdf. Acesso em 14 out. 2017.

BRANNEN, M. Y. Using multiple case studies to generalize from ethnographic research. In: PIEKKARI, R.; WELCH, C. Rethinking the case study in international business and management research. UK: Edward Elgar Publishing Limited, 2011.

CARNEIRO, A. M. M. Teorias organizacionais: do ceticismo à consciência crítica. Revista de Administração Pública, v. 29, n. 2, p. 51-70, 1995.

CHANLAT, J. F. Ciências sociais e management: reconciliando o econômico e o social. São Paulo: Atlas, 100, 2000.

CHANLAT, J. F. O indivíduo e a organização: dimensões esquecidas. Tradução: Rodrigues, M. et al. 2.ed. São Paulo: Atlas, v. 1, 1993.

CORÁ, M. A. J. Empreendedores criativos: uma análise sobre o tralhado na cultura. Revista Interdisciplinar de Gestão Social, Salvador, v. 5, n. 2, p.71-89, mai./ago. 2016.

CUNHA, M. H. Gestão cultural: profissão em formação. Belo Horizonte. Duo, 2007.

DAVEL, E.; SANTOS, L. A. D. Improvisação como competência cultural: uma autoetnografia da atividade gerencial no setor público. Gestão \& Conexões, Vitória (ES). v. 4, n. 1, p. 91-115, jan./ jun. 2015. DOI: https://doi.org. 10.13071/regec.2317-5087.2015.4.1.8017.91-115

DAVEL, E. P. B.; OLIVEIRA, C. A. A Reflexividade intensiva na aprendizagem organizacional: uma autoetnografia de práticas em uma organização educacional. Organizações \& Sociedade, Salvador, v. 25, n. 85, p. 211-228, abr./jun. 2018. DOI: https://doi.org/10.1590/1984-9250852.

DIAS, J. S.; COSTA, L. F. Cultura, território e política regional no estado da Bahia, Brasil. Córima, Revista De Investigación En Gestión Cultural, México, v. 3, n.4, p.1-20, enero/junio 2018. DOI: https://doi.org/10.32870/cor.a3n4.7067.

DELEUZE, G. Post-Scriptum sobre as sociedades de controle. Conversações 1972-1990. RJ: Ed. 34, p. 219-226,1992. 
DURAND, J. C. G. Profissionalizar a administração da cultura. Revista de administração de empresas, São Paulo, v. 36, n. 2, p. 6-11, junho de 1996. DOI: https://doi. org/10.1590/S0034-75901996000200002.

DURAND, J. C. G. Política e gestão cultural: Brasil, USA e Europa. 2000.

EAGLETON, T. A ideia de cultura. Lisboa: Temas e Debates, 2003.

ELLIS, C., BOCHNER, A. P. Autoethnography, personal narrative, reflexivity: researcher as subject. In: DENZIN, N. K.; LINCOLN, Y. S. Handbook of qualitive research. London: Sage Publication, 2000.

ELLIS, C.; ADAMS, T. E.; BOCHNER, A. P. Autoethnography: An Overview. Forum Qualitative Sozialforschung / Forum: Qualitative Social Research, [S.I.], v. 12, n. 1, nov. 2010. Available at: <http://www.qualitative-research.net/index.php/fqs/article/view/1589/3096>. Date accessed: 25 may 2020. doi: https://dx.doi.org/10.17169/fqs-12.1.1589.

ENRIQUEZ, E. O indivíduo preso na armadilha da estrutura estratégica. Revista de Administração de Empresas, São Paulo, v.37, n.1, jan-mar, p.18-29, 1997. DOI: https://dx.doi.org/10.1590/S0034-75901997000100003.

FERREIRA, C. G. A gestão e o gestor cultural: uma análise de características. Revista do Centro de Pesquisa e Formação, São Paulo, n.1, p. 37-50, nov. 2015.

FORTIN, S. Contribuições possíveis da etnografia e da auto-etnografia para a pesquisa na prática artística. Cena, Porto Alegre, n.7, p.77-88, 2009. DOI: https://doi.org/10.22456/22363254.11961.

GEERTZ, C. Uma Descrição Densa: por uma teoria interpretativa da cultura. A interpretação das culturas. Rio de Janeiro: Editora Guanabara Koogan, 1989, p.13-41.

GEERTZ, C. Uma descrição densa: por uma teoria interpretativa da cultura. In: A interpretação das culturas. Rio de Janeiro: LTC; 2008, p.3-24.

GOMES, V. M. L. R et al. Um estudo preliminar sobre os sentidos da estratégia organizacional: possíveis relações entre textos institucionais e o noticiário de negócios. In: III Sico. Seminário Internacional de Comunicação Organizacional. PPGCOM. Minas Gerais. Anais [...]. Minas Gerais: Universidade Federal de Minas Gerais, 2016. Disponível em: https://congressos.ufmg.br/index.php/sico2016/sico2016. Acesso em: 20 nov. 2018.

HACKLEY, C.; HACKLEY, R. A. Autoethnography and subjective experience in marketing and consumer research. Revista Interdisciplinar de Marketing, Maringá, v. 6, n. 1, p. 3-10, 2016. DOI: https:/doi.org/10.4025/rimar.v6i1.28115.

HANCOCK, B.; OCKLEFORD, E.; WINDRIDGE, K. Na introduction to qualitative research. The NIHR RDSEM/ YH, 2007. 
HELOANI, R. Gestão e Organização no Capitalismo Globalizado: história da manipulação psicológica no mundo do trabalho. São Paulo: Atlas, 2007.

KOCK, K. F.; GODOI, C. K.; LENZI, F. C. Discussão e prática da autoetnografia: um estudo sobre aprendizagem organizacional em uma situação de catástrofe. Revista Gestão Organizacional, Chapecó, v. 5, n. 1, p. 93-106, 2012. DOI: https:/doi.org/10.22277/rgo.v5i1.1249.

LIMA, L.C. Questões sobre uma cultura periférica. In: Seminário Diversidade Cultural Brasileira. Salvador. Anais [...] Salvador: Fundação Casa Rui Barbosa, 2004. Disponível em: http://www.casaruibarbosa.gov.br/dados/DOC/palestras/Diversidade_Cultural/FCRB_Divers idadeCulturalBrasileira_LuizCostaLima.pdf. Acesso em: 05 out. 2019.

MAGALHÃES, C. E. A. Autoetnografia em contexto pedagógico: entrevista e reunião como lócus de investigação. Veredas Temática: Autoetnografia em Estudos da Linguagem e áreas interdisciplinares, Juiz de Fora, v. 22, n. 1, p. 16-33, 2018.

MARINO, A. Cultura, periferia e direito à cidade: coletividade em São Paulo e Bogotá.

Políticas Públicas \& Cidade, Belo Horizonte, v. 3, n. 3, p. 4-25, 2015.

MELO, M. C. O. L. Categoria Gerencial e seus Conflitos nas Relações de Trabalho, Buenos Aires. In: III Congreso Latinoamericano de Sociología del Trabajo. Buenos Aires, Anais [...]. Buenos Aires, Argentina, 2000. Meio magnético.

MERRIAM, S. B. A. Qualitative research in practice: examples for discussion and analysis (1st ed.). San Francisco, CA: Jossey-Bass, 2002.

MINTZBERG, H. et. al. Safári de Estratégia. Porto Alegre: Ed. Bookmam, 2004.

MINTZ, S.W. Cultura: uma visão antropológica. Tempo, Niterói, v. 14, n. 28, p. 223-237, jun. 2010. DOI: https://doi.org/10.1590/S1413-77042010000100010.

PAES de PAULA, A.P. Guerreiro Ramos: resgatando o pensamento de um sociólogo crítico das organizações. Organizações \& Sociedade, Salvador, v. 14, n. 40, p. 169-188, 2007. DOI: https://doi.org/10.1590/S1984-92302007000100010.

PORÉM, M. E.; VERAS T. S. F. Comunicação e estratégia nas organizações: a soma das partes e o todo. In: III Sico. Seminário Internacional de Comunicação Organizacional. PPGCOM. Minas Gerais. Anais [...]. Minas Gerais: Universidade Federal de Minas Gerais, 2016. Disponível em: http://professor.ufrgs.br/sites/default/files/elisangela-lasta/files/pdf.pdf. Acesso em: 30 maio 2019.

RAMOS, A. G. Models of man and administrative theory. Public Administration Review, p. 241-246, 1972.

RAMOS, A. G. A nova ciência das organizações: uma reconceitualização das riquezas das nações. Rio de Janeiro: FGV, 1981. 
REBECHI, C. A mobilização da subjetividade do trabalhador como estratégia de comunicação nas organizações. In: III Sico. Seminário Internacional de Comunicação Organizacional. Minas Gerais. Anais [...] Minas Gerais: Universidade Federal de Minas Gerais, 2016. Disponível em: http://professor.ufrgs.br/sites/default/files/elisangela-lasta/files/pdf.pdf. Acesso em: 30 maio 2019.

REED, M. Sociologia da gestão. Oeiras: Celta,1997.

ROCHA, J. C. C. Dialética da marginalidade - caracterização da cultura brasileira contemporânea. Especial para folha + mais. São Paulo, domingo, 29 de fevereiro de 2004. Disponível em: https://www1.folha.uol.com.br/fsp/mais/fs2902200404.htm Acesso em: 30 jul. 2019.

RODRIGUES, C. Os nomes do capital. Serrote, v. 9, p. 103-117, 2011.

SANSON, C. A produção biopolítica é constitutiva ao capitalismo cognitivo. Liinc em Revista, Rio de Janeiro: IBICT, v. 5, n. 2, p. 206-214, 2009. DOI:

https://doi.org/10.18617/liinc.v5i2.308

SANTOS, M. O dinheiro e o território. Revista GEographia, Nitéroi, v.1, n. 1, p. 7-13, 1999. DOI: https://doi.org/10.22409/GEOgraphia1999.v1i1.a13360.

SANTOS, M. O retorno do território. In: OSAL: Observatorio Social de América Latina. Año 6 no. 16 (jun. 2005). Buenos Aires: CLACSO, 2005. Disponible en:

http://bibliotecavirtual.clacso.org.ar/ar/libros/osal/osal16/D16Santos.pdf. Acesso em: 25 maio 2019.

SANTOS, C. M.; BIANCALANA, G. R. Autoetnografia: um caminho metodológico para a pesquisa em artes performativas. Revista Aspas, Santa Maria, v. 7, n. 2, p. 83-93, 2017. DOI: https://doi.org/10.11606/issn.2238-3999.v7i2p53-63.

SERVA, M. A racionalidade substantiva demonstrada na prática administrativa. Revista de administração de empresas, São Paulo, v. 37, n. 2, p. 18-30, 1997. DOI: https://dx.doi.org/10.1590/S0034-75901997000200003.

SOARES, F. M. A produção de subjetividades no contexto do capitalismo contemporâneo: Guattari e Negri. Fractal: Revista de Psicologia, Rio de Janeiro, v. 28, n.1, p. 118-126, jan./abr., 2016. DOI: https://doi.org/10.1590/1984-0292/1170.

SOMMER, D. Liberdades literárias: a autoridade dos autores afrodescendentes. In: FUENTE, A. et al. Coordinación general de Andrews, G.R. \& Fuente, A. Estudos afrolatino-americanos: uma introdução. Ciudad Autónoma de Buenos Aires: CLACSO, 2018, p. 375- 408.

TENÓRIO, F. G. Tem razão a administração? Revista de Administração Pública, Rio de Janeiro, v. 24, n. 2, p. 5-9, 1990. 
TOMEI, P. A.; FERRARI, P. J. Gestão cultural em negócios familiares. Brazilian Business Review, Vitória (ES), v.7, n. 3, p. 24-46, 2010.

WEBER, M. Ensaios de sociologia. Rio de Janeiro: LTC, 1982.

VIEIRA, A.; AMARAL, G. A. A arte de ser Beija-Flor na tripla jornada de trabalho da mulher. Saúde e Sociedade, São Paulo, v. 2, n. 2, p. 403-414, 2013. DOI: https://doi. org/10.1590/S0104-12902013000200012. 